\title{
Polymorphism of the RAGE Affects the Serum Inflammatory Levels and Risk of Ischemic Stroke in a Chinese Population
}

\author{
XiaoPing Cuia ${ }^{a, d}$ HongJie Chen ${ }^{a, d}$ Xuwei Hou ${ }^{b}$ ShouSen Wang ${ }^{a}$ Shoba Jayaram ${ }^{c}$ \\ ZhaoCong Zhenga \\ aDepartment of Neurosurgery, Fuzhou General Hospital of Xiamen University, Fujian, ${ }^{b}$ Department \\ of Cardiology, Hangzhou First Municipal Hospital, Hangzhou, China; 'Sangolli Nursing Home 270, \\ Mahalakshmi Layout, Bangalore, India; 'author contributed equally
}

\section{Key Words}

Polymorphisms - Receptor for advanced glycation end products - Stroke - Susceptibility • Inflammation

\begin{abstract}
Background: Increasing evidence shows that inflammation plays an important role in the occurrence and progression of acute ischemic stroke. The receptor for advanced glycation end products (RAGE) has been documented to involve in the pathogenic mechanisms of a variety of neurological diseases, including ischemic stroke (IS). However, the impact of RAGE gene polymorphisms on the susceptibility to IS has not been reported. We thus explored the association between RAGE gene polymorphisms and the susceptibility to IS. Method: A total of 384 patients with IS and 425 healthy controls were enrolled in this study. Three genetic polymorphisms of RAGE gene (82G/S, $-429 T / C$ and $-374 T / A)$ were determined. The serum levels of soluble RAGE (sRAGE), intetleukin-6 (IL-6), high sensitivity-C reaction protein (hsCRP) and plasminogen activator inhibitor-1 (PAI-1) were detected. Results: Among the studied polymorphisms, only the polymorphism at $82 \mathrm{G} / \mathrm{S}$ of RAGE gene was associated with the risk for ischemic stroke irrespective of the stroke subtypes. The 82S/S homozygote carriers had a significantly increased risk for ischemic stroke [adjusted odds ratio (OR): $2.297 ; p<0.001$ ]. The haplotype analyses showed that the $\mathrm{C}_{-429} \mathrm{~S}_{82} \mathrm{~T}_{-374}$ and $\mathrm{T}_{-429} \mathrm{~S}_{82} \mathrm{~A}_{-374}$ had higher risk to develop IS $(\mathrm{OR}=1.864$ and 1.931, respectively, all $\mathrm{p}<0.01)$, while the $\mathrm{C}_{-429} \mathrm{G}_{82} \mathrm{~T}_{-374}$ showed a protective effect against IS susceptibility $(\mathrm{OR}=0.568, \mathrm{p}=0.001)$. In addition, the $82 \mathrm{~S} / \mathrm{S}$ homozygote carriers had a higher inflammatory level compared with $82 \mathrm{G} / \mathrm{S}$ and $82 \mathrm{G} / \mathrm{G}$ genotypes, indicated by lower serum sRAGE level, higher serum IL-6, hs-CRP and PAI-1 levels. The polymorphisms at -374 and -429 loci did not influence the stroke risk and the above mentioned inflammation cytokines. Conclusion: Our results showed a close correlation between the $82 \mathrm{G} / \mathrm{S}$ polymorphism and the susceptibility to IS, suggesting the $82 \mathrm{G} / \mathrm{S}$ polymorphism may be used as a genetic marker for the prediction of stroke occurrence in high risk subjects.
\end{abstract}

Copyright (C) 2013 S. Karger AG, Basel 
Cui et al.: RAGE Gene Polymorphism and the Susceptibility to IS

\section{Introduction}

Ischemic stroke (IS) is a major cause of death and disability in many countries. Several environmental factors, such as hypertension, diabetes, atrial fibrillation, smoking and chronic kidney disease have been identified as risk factors for IS [1, 2]. However, these factors only account for a proportion of stroke risk. Studies showed that nearly one-half of stroke risk can be attributed to genetic risk factors $[3,4]$. To date, several candidate genes have been shown to influence the stroke risk in different populations [5-8]. Recently, increasing evidence shows that inflammation plays an important role in the occurrence and progression of acute ischemic stroke [9-12]; thus, the roles of genetic variants of the inflammation related gene attract much interest.

The receptor for advanced glycation end products (RAGE) is a member of the immunoglobulin superfamily of cell surface molecules and a receptor for advanced glycation end products (AGEs) $[13,14]$. AGE-RAGE interaction alters several cell functions through modulation of multiple intracellular signaling pathways [15]. The RAGE is expressed in various cell types including neurons. In brain, RAGE is present on neurons, glia, and endothelial cells [16]. The RAGE has been demonstrated to play a central role in the pathogenic mechanisms of a growing number of neurological diseases, e.g. Alzheimer's disease (AD) and stroke [17-19]. The role of RAGE in the pathophysiology of acute ischemia was directly documented by using genetic RAGE deficiency animal model of cerebral ischemia [20]. RAGE contribute to delayed neuronal death after global cerebral ischemia by enhancing vascular injury and deleterious glia-mediated inflammation [21]. The plasma levels of soluble RAGE (sRAGE) is reported to be a biomarker for the risk and severity of acute ischemic stroke, especially in those without a source of cardio-embolism [22]. Circulating sRAGE reflects vascular inflammation status $[21,23]$. Neuronal RAGE expression modulates severity of injury following transient focal cerebral ischemia, indicating that RAGE signaling directly contributes to pathology in cerebral ischemia [18].

RAGE is encoded by chromosome 6 at the major histocompatibility locus (MHC) class II/III junction. To date, more than 20 several single nucleotide polymorphisms (SNP) in the RAGE gene have been identified [24], amongst which, $-429 \mathrm{~T}>\mathrm{C}$ (rs1800625), $-374 \mathrm{~T}>\mathrm{A}$ (rs1800624), G82S (g.555G>A, rs2070600) were mostly studied. The role of the polymorphisms of RAGE gene in several disease conditions, e.g., coronary artery disease (CAD), heart failure, nephropathy, chronic renal insufficiency with diabetes have been previously documented [25-29].

Considering the role of RAGE in inflammation and the pathophysiology of ischemic stroke, we postulate there might be a possible association between the polymorphisms of RAGE gene and stroke. In the present study, we enrolled patients with ischemic stroke from a Chinese population to explore the role of RAGE gene polymorphisms in determining the susceptibility of ischemic stroke.

\section{Materials and Methods}

A total of 384 patients were included in this study from August 2006 to July 2009. All the patients were diagnosed as having first ever IS by at least two independent neurologists. The diagnosis of IS were confirmed based on strict neurological examination, computed tomography or magnetic resonance imaging, according to the criteria of Trial of ORG 10172 in Acute Stroke Treatment (TOAST) [30]. According to these criteria, we enrolled only patients with subtype of small vessel disease (SVD) and large vessel disease (LVD). Patients with the subtypes, such as cardio-embolism, stoke of other determined etiology and stroke of undetermined etiology were not included in this study. The other exclusive criteria included: recurrent IS, cerebrovascular malformations, brain tumors and traumatic cerebrovascular diseases, cardiovascular diseases, peripheral vascular diseases, atrial fibrillation, infections and malignant disorders. A total of 425 unrelated age and sex matched healthy volunteers were included in this study as controls. All these controls were enrolled among participants examined through annual health check-up program. Controls with stroke history, neurological 
Cui et al.: RAGE Gene Polymorphism and the Susceptibility to IS

diseases, ischemic heart diseases or any chronic diseases were excluded. All the participants were ethnically Chinese Han and all were from southeast China area. Main clinical data including age, sex, body mass index, smoking history, arterial hypertension, diabetes mellitus (DM), and family history of stroke were recorded. Fasting blood samples were collected from patients and controls. Body mass index was calculated as the weight divided by height squared (BMI, $\mathrm{kg} / \mathrm{m} 2$ ). Hypertension referred to as have a previous diagnosis of hypertension by a Physician, and use a prescription antihypertensive medication and/or have a systolic $\mathrm{BP} \geq 145 \mathrm{~mm} \mathrm{Hg}$ and/or a mean diastolic BP $\geq 95 \mathrm{~mm} \mathrm{Hg}$ during interview. The smoker category included current smokers who smoke daily. Non consumers of tobacco were defined as persons who had never smoked or had consumed less than 20 packs of cigarettes or $360 \mathrm{~g}$ of tobacco in their lifetime or less than one cigarette per day [31]. Total cholesterol (TC), triglyceride (TG), high density lipoprotein-cholesterol (HDL-C), low density lipoprotein-cholesterol (LDL-C), glucose levels and high sensitivity-C reactive protein (hs-CRP) were determined. The study was approved by the ethics committee of our hospital and informed consent was obtained from all participants.

\section{Detection of serum inflammatory factors}

Blood samples were taken immediately when the diagnosis was established in 150 patients with newly diagnosed first ever acute ischemic stroke. sRAGE levels in sera were determined by RAGE Immunoassay (R\&D Systems, Minneapolis, MN, USA) in an ELISA format, with wells coated with murine anti-human RAGE $\mathrm{mAb}$ in which serum samples ( $50 \mu \mathrm{l} /$ well, normally $1: 2 \mathrm{v} / \mathrm{v}$ dilution) were incubated. A polyclonal capture antibody against the extracellular domain of RAGE was used for detection. The minimum detectable sRAGE concentration is $4.12 \mathrm{pg} / \mathrm{ml}$, according to the manufacturer and the inter-assay coefficient of variation is < 8\%. Other cytokines [included serum intetleukin-6 (IL-6), high sensitivity-C reaction protein (hs-CRP) and plasminogen activator inhibitor-1 (PAI-1)] were measured using a Luminex IS 100 instrument (Bio-Rad, Hercules, CA.). The coefficient of variation for controls ranged from 9 to $19 \%$ on the exponential phase of the standard curve.

\section{Genotyping}

Genotyping was performed by polymerase chain reaction-restriction fragment length polymorphism (PCR-RFLP) using AluI (Invitrogen) and Tsp509I (New England Biolabs) for 82G $>$ S, $-429 \mathrm{~T}>\mathrm{C}$ and $-374 \mathrm{~T}>\mathrm{A}$ variations respectively, as described by Hudson et al. and Gu et al. [32, 33]. RFLPs were resolved using $10 \%$ polyacrylamide gel electrophoresis, stained with ethidium bromide and registered with a UVP BioChemi system.

\section{Statistical Analysis}

Continuous variables were tested for normality (Kolmogorov-Smirnov test). Variables with normal distribution describe as mean \pm standard deviation. Variables without normal distribution, e.g., HDL-C, LDL-C, TC and TG were expressed as median (interquartile range $=25 \%-75 \%$ interquartile). Data on qualitative characteristics were expressed as percent values or absolute numbers, as indicated. Differences in demographic characteristics and vascular risk factors between patients and controls were compared by using Student's t test or ANOVA for continuous variables and the $\chi 2$ test for all categorical variables. Tests for Hardy-Weinberg equilibrium were conducted using $\chi 2$ tests. Genotypes and allele frequencies were compared by $\chi 2$ analysis or Fisher's exact test. Multivariate logistic regression analysis was used to determine the influence of RAGE polymorphisms on stroke risk, controlling potential confounding risk variables including age, sex, and other conventional risk factors. A forward stepwise (Likelihood Ratio) procedure was used for multivariable analysis. The associations between the RAGE haplotypes and IS risk were analyzed. The D' value for the studied 4 SNPs were calculated with the SHEsis software [34]. Data were analyzed with the SAS 9.3 package (SAS Inc.NC, USA) and results were considered statistically significant at $\mathrm{p}<0.05$ using a 2 -tailed test.

\section{Results}

Demographic data and risk factor profiles of patients and controls are presented in Table 1. There were no significant differences between stroke and controls with regards to 
Cui et al.: RAGE Gene Polymorphism and the Susceptibility to IS

Table 1. Anthropometric and laboratory characteristics of the studied groups. TC, Total cholesterol; TG, triglyceride; HDL-C, high density lipoprotein-cholesterol; LDL-C, low density lipoprotein-cholesterol; T2DM, Type 2 diabetes mellitus; BMI, body mass index; hs-CRP, high sensitivity- $C$ reactive protein; PAI-1, plasminogen activator inhibitor-1; IL-6, interleukin-6; sRAGE, soluble RAGE

\begin{tabular}{llll}
\hline & \multicolumn{1}{c}{ Stroke subjects } & \multicolumn{1}{c}{ Control } & P \\
\hline Age (years) & $61.2 \pm 7.5$ & $61.1 \pm 6.2$ & 0.543 \\
Male/Female & $199 / 185$ & $211 / 214$ & 0.112 \\
BMI (kg/m2) & $23.1 \pm 3.2$ & $22.9 \pm 2.8$ & 0.052 \\
Hypertension (\%) & $255(66.40 \%)$ & $210(49.41 \%)$ & $<0.001$ \\
T2DM (\%) & $147(38.28 \%)$ & $108(25.41 \%)$ & 0.011 \\
Smoker (\%) & $178(46.35 \%)$ & $201(47.29 \%)$ & 0.074 \\
HDL-C (mmol/L) & $2.09(1.17-3.32)$ & $2.24(1.18-2.26)$ & 0.052 \\
LDL-C (mmol/L) & $1.73(1.14-2.21)$ & $1.22(0.67-2.11)$ & 0.003 \\
TC (mmol/L) & $4.31(2.54-5.56)$ & $4.32(2.23-5.34)$ & 0.115 \\
TG (mmol/L) & $3.08(1.77-5.14)$ & $2.96(1.56-3.78)$ & 0.055 \\
hs-CRP (mg/L) & $7.65(5.34-10.12)$ & $2.11(1.21-3.37)$ & $<0.001$ \\
IL-6 (pg/mL) & $24.13(17.37-33.37)$ & $5.67(3.45-8.65)$ & $<0.001$ \\
PAI-1 level (ng/mL) & $18.46(15.58-26.34)$ & $11.27(5.65-16.11)$ & $<0.001$ \\
sRAGE level ( pg/mL) & $656.45(452.65-1096.45)$ & $854.43(598.41-1201.36)$ & $<0.001$ \\
\hline
\end{tabular}

gender, BMI, TC, TG levels and smoking. However, hypertension and diabetes were more prevalent in ischemic stroke subjects than controls ( $\mathrm{p}<0.001$ and $\mathrm{p}=0.011$, respectively). In addition, the LDL-C levels were higher in stroke subjects than in controls $(p=0.007)$. Compared with controls, the stroke subjects had a significantly higher hs-CRP $(7.98 \pm 1.22 \mathrm{vs}$ $1.96 \pm 1.19, \mathrm{mg} / \mathrm{L}, \mathrm{p}<0.001), \mathrm{IL}-6(23.50 \pm 3.95$ vs $4.93 \pm 2.01, \mathrm{pg} / \mathrm{mL}, \mathrm{p}<0.001)$ and PAI-1 level $(17.09 \pm 2.99$ vs $11.81 \pm 2.75, \mathrm{ng} / \mathrm{mL}, \mathrm{p}<0.001)$, but lower in sRAGE level $(700.73 \pm 105.9$ vs 878.78 $\pm 136.27, \mathrm{pg} / \mathrm{mL}, \mathrm{p}<0.001)$.

Table 2 describes the genotype distributions and allele frequencies of RAGE polymorphisms in stroke and control subjects. The genotype frequencies for all polymorphisms did not differ significantly from those expected under Hardy-Weinberg equilibrium (all p>0.05). Generally, there were no significant differences of genotype distributions and alleles frequencies of $-429 \mathrm{~T} / \mathrm{C}$ and $-374 \mathrm{~T} / \mathrm{A}$ between stroke subjects and control subjects (all p>0.05, Table 2). However, genotype and allele frequencies at $82 \mathrm{G} / \mathrm{S}$ locus were significantly different between stroke subjects and control subjects. The presence of $82 \mathrm{~S} / \mathrm{S}$ genotype and $82 \mathrm{~S}$ allele were significantly higher in stroke subjects than in controls (both $\mathrm{p}<0.001$ ). We further performed multivariate logistic regression analysis to determine whether the 82S/S genotype or $82 \mathrm{~S}$ allele was independent risk factors for stroke. The presence of ischemic stroke was considered as the outcome variable and the following variables were used as covariates: age, sex, TG, TC (HDL-C and LDL-C), hypertension, smoking, BMI, hs-CRP levels and DM. With the 82G/G genotype as reference, the presence of 82S/S homozygotes had a significantly increased risk for stroke (OR: 2.297; 95\% CI: 1.583---3.333, p<0.001, Table 2) after adjustment with the above mentioned clinical variables. The $82 \mathrm{~S}$ allele carriage presented a higher risk factor (adjusted $\mathrm{OR}=1.610,95 \% \mathrm{CI}$ : $1.322-1.960, \mathrm{p}<0.001)$. The polymorphisms at $-429 \mathrm{~T} / \mathrm{C}$ and $-374 \mathrm{~T} / \mathrm{A}$ of RAGE gene did not influence the susceptibility of stroke in this study.

The associations between the RAGE haplotypes and stroke risk were analyzed in this study. The $\mathrm{D}^{\prime}$ value and $\mathrm{r} 2$ for the studied 3 SNPs were calculated with the SHEsis software [35]. All 3 SNPS were in strong LD (all $D^{\prime}>0.8$ ). The estimated haplotype frequencies of the RAGE SNPs are shown in Table 3. The haplotype of $\mathrm{C}_{-429} \mathrm{~S}_{82} \mathrm{~T}_{-374 \text { and }} \mathrm{T}_{-429} \mathrm{~S}_{82} \mathrm{~A}_{-374}$ were 


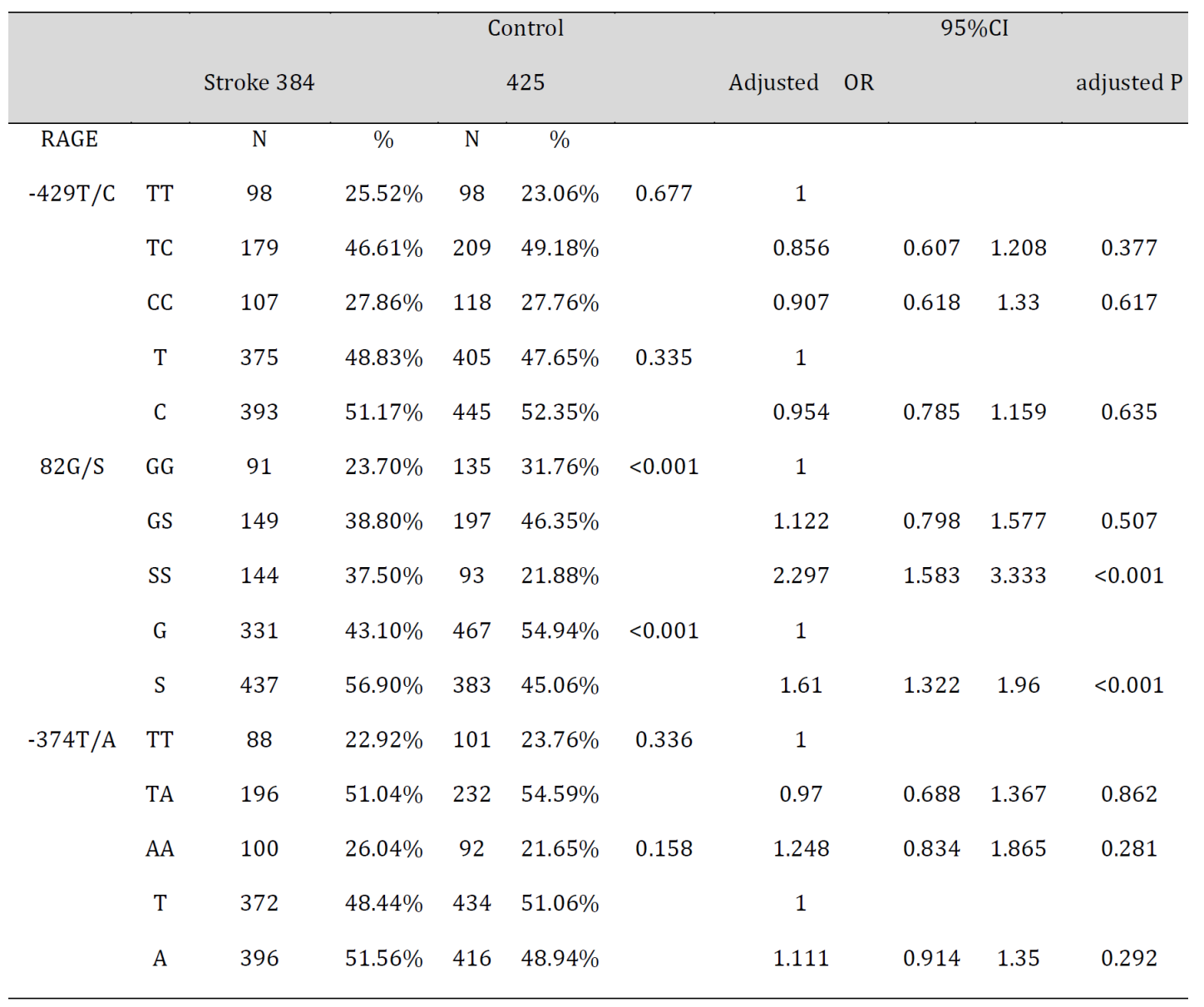

Table 2. Genotype and allele frequencies of RAGE polymorphism in the studied groups. Values were in number $(\mathrm{N})$ and percentage (\%), $\chi 2$, chi-square test; $95 \% \mathrm{CI}, 95 \%$ confidence interval; adjusted OR, adjusted odds ratio. All groups were in Hardy-Weinberg equilibrium

Table 3. Haplotype frequencies of the RAGE polymorphisms in the studied groups. (All those frequency<0.03 will be ignored in analysis.) OR, odds ratio; 95\% CI, 95\% confidence interval; freq, frequency

\begin{tabular}{llllll}
\hline & Stroke(freq) & Control(freq) & Chi2 & P & OR :95\%CI \\
\hline C G A & $141.10(0.166)$ & $123.12(0.160)$ & 0.096 & 0.757 & $1.043[0.801 \sim 1.358]$ \\
C S T & $137.07(0.161)$ & $71.82(0.094)$ & 16.472 & $<0.001$ & $1.864[1.375 \sim 2.526]$ \\
C S A & $106.30(0.125)$ & $106.74(0.139)$ & 0.685 & 0.408 & $0.885[0.664 \sim 1.181]$ \\
C G T & $60.53(0.071)$ & $91.33(0.119)$ & 10.797 & 0.001 & $0.568[0.404 \sim 0.799]$ \\
T S A & $51.63(0.061)$ & $24.88(0.032)$ & 7.192 & 0.007 & $1.931[1.185 \sim 3.148]$ \\
T G T & $137.20(0.161)$ & $111.18(0.145)$ & 0.859 & 0.354 & $1.137[0.867 \sim 1.492]$ \\
T S T & $99.20(0.117)$ & $97.68(0.127)$ & 0.414 & 0.52 & $0.907[0.673 \sim 1.222]$ \\
\hline
\end{tabular}

significantly more frequent in stroke subjects than controls $(16.1 \%$ vs $9.4 \%$ and $6.1 \%$ vs $3.2 \%$, respectively), while the $\mathrm{C}_{-429} \mathrm{G}_{82} \mathrm{~T}_{-374}$ was much lower in stroke subjects than controls (7.1\% vs $11.9 \%$, Table 3 ). Our data showed haplotype of $\mathrm{C}_{-429} \mathrm{~S}_{82} \mathrm{~T}_{-374}$ and $\mathrm{T}_{-429} \mathrm{~S}_{82} \mathrm{~A}_{-374}$ had significantly higher risks to develop IS (OR=1.864 and 1.931 , respectively, all $\mathrm{p}<0.01$ ). In contrast, the $\mathrm{C}_{-429} \mathrm{G}_{82} \mathrm{~T}_{-374}$ showed a protective for IS susceptibility (OR=0.568, $\mathrm{p}=0.001$ ). 
Cui et al.: RAGE Gene Polymorphism and the Susceptibility to IS

Table 4. Genotype distributions and alleles frequencies of $82 \mathrm{G} / \mathrm{S}$ according to stroke type. SVD, small vessel disease; LVD, large vessel disease

\begin{tabular}{rrrrrrr}
\hline Type & RAGE & $\mathrm{N}$ & $\%$ & $\mathrm{~N}$ & $\%$ & $\mathrm{P}$ \\
\hline LVD & GG & 44 & $23.78 \%$ & 35 & $30.57 \%$ & $<0.001$ \\
& GS & 68 & $36.76 \%$ & 68 & $59.39 \%$ & \\
& SS & 73 & $39.46 \%$ & 20 & $17.47 \%$ & \\
& G & 156 & $42.16 \%$ & 138 & $56.10 \%$ & $<0.001$ \\
& SVD & 214 & $57.84 \%$ & 108 & $43.90 \%$ & \\
& GG & 47 & $23.62 \%$ & 73 & $36.68 \%$ & $<0.001$ \\
& GS & 81 & $40.70 \%$ & 92 & $46.23 \%$ & \\
& SS & 71 & $35.68 \%$ & 34 & $17.09 \%$ & \\
& G & 175 & $43.97 \%$ & 238 & $59.80 \%$ & $<0.001$ \\
& S & 223 & $56.03 \%$ & 160 & $40.20 \%$ & \\
\hline
\end{tabular}

We further stratified the patients, according to stroke type, into small vessel disease (SVD) and large vessel disease (LVD) groups. The stroke subtypes were classified using the Trial of ORG 10172 in Acute Stroke Treatment (TOAST) [30]. We found that the genotype distributions and alleles frequencies of 82G/S were significantly different in both SVD and LVD subgroups (all $p<0.001$, Table 4). The presence of $82 \mathrm{~S}$ was significantly higher in both SVD and LVD than in controls (both $\mathrm{P}<0.001$, Table 4).

We further analyzed the serum cytokines levels in the stroke and control subjects according to the 82G/S genotype distributions. The 82S/S carriers had a lower sRAGE levels $(611.58 \pm 131.32$ vs $789.39 \pm 158.67, \mathrm{pg} / \mathrm{mL}, \mathrm{p}=0.015)$, however, had a markedly higher CRP (9.346 \pm 1.36 vs.7.302 \pm 1.12 and $7.307 \pm 1.10, \mathrm{mg} / \mathrm{L}, \mathrm{p}=0.032$ and 0.035 , respectively), IL-6 (26.32 \pm 3.45 vs $22.64 \pm 3.501$ and $21.55 \pm 4.9, \mathrm{pg} / \mathrm{mL}, \mathrm{p}=0.025$ and 0.019 , respectively) and PAI-1 levels $(19.4 \pm 2.33$ vs.17.44 \pm 2.67 and $14.45 \pm 3.98, \mathrm{ng} / \mathrm{mL}, \mathrm{p}=0.046$ and 0.012 , respectively), compared with $82 \mathrm{G} / \mathrm{S}$ and $82 \mathrm{G} / \mathrm{G}$ carriers (Fig.1 A-D).

\section{Discussion}

In the present study, we studied the possible association between the RAGE gene polymorphisms and IS in a Chinese cohort. Of the three loci studied, we found that only the polymorphisms at $82 \mathrm{G} / \mathrm{S}$ were associated with the risk for IS. The $82 \mathrm{~S} / \mathrm{S}$ homozygote carriers had a significantly increased risk for ischemic stroke (adjusted OR: 2.297; $\mathrm{p}<0.001$ ). The haplotype analyses showed that the $\mathrm{C}_{-429} \mathrm{~S}_{82} \mathrm{~T}_{-374 \text { and }} \mathrm{T}_{-429} \mathrm{~S}_{82} \mathrm{~A}_{-374}$ had higher risk to develop IS (OR=1.864 and 1.931, respectively, all $\mathrm{p}<0.01)$, while the $\mathrm{C}_{-429} \mathrm{G}_{82} \mathrm{~T}_{-374}$ showed a protective for IS susceptibility $(\mathrm{OR}=0.568, \mathrm{p}=0.001)$. Notably, we found that the $82 \mathrm{~S} / \mathrm{S}$ homozygote carriers had a higher inflammatory status compared with G/S and G/G genotypes, indicated by lower sRAGE level, higher IL-6, hs-CRP and PAI-1 levels. The polymorphisms at -374 and -429 loci did not influence the stroke risk and the above mentioned inflammation cytokines. Our findings in this study suggest that the $82 \mathrm{G} / \mathrm{S}$ may be used as a genetic marker for the prediction of stroke occurrence in high risk subjects.

The 82G/S (82Gly $\rightarrow$ Ser) functional polymorphisms in the RAGE gene was one of the first identified polymorphisms of the RAGE gene and occurs in the ligand-binding V-domain of RAGE and therefore has attracted considerable interest [36]. The 82S allele enhances the ligand-binding affinity and increased the ligand-stimulated generation of inflammatory mediators in transfected cells and human monocytes compared to the common RAGE 82Gly 


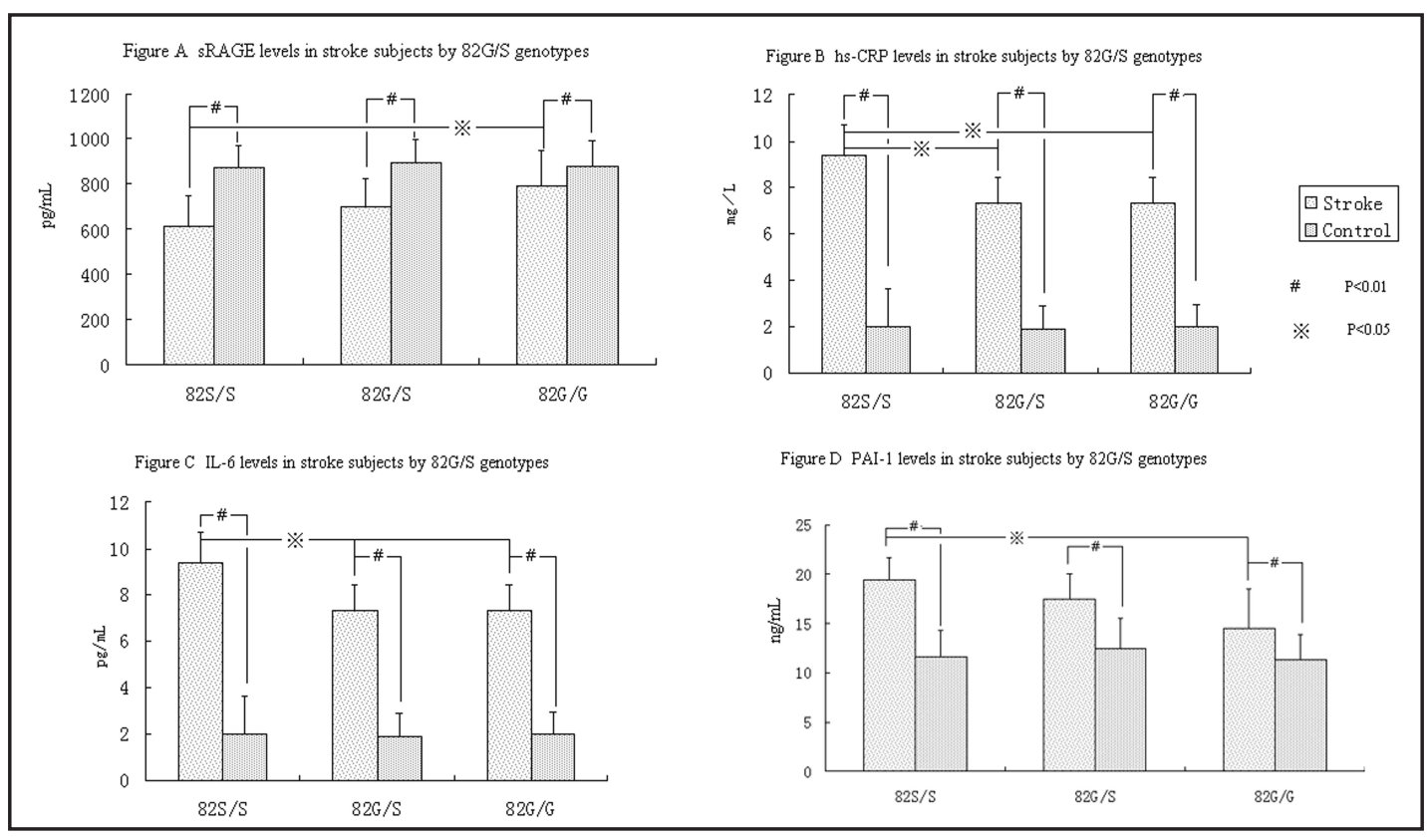

Fig. 1. A-D. The serum cytokines levels in the stroke and control subjects according to the $82 \mathrm{G} / \mathrm{S}$ genotype distributions.

allele. Recent observations indicated that the Gly82Ser polymorphism was associated with various diseases, including skin complications in type 2 diabetes, diabetic advanced nephropathy, coronary artery disease, and rheumatoid arthritis [36-38] .

Recently, RAGE is view as a novel biological and genetic marker for vascular disease. The association between the $82 \mathrm{G} / \mathrm{S}$ polymorphism and cardiovascular disease is quite inconsistent. Jang et al. have reported that subjects with the SS homozygous mutation of the G82S polymorphism had increased risk factors for cardiovascular disease compared with those bearing at least one $G$ allele in non-diabetic and non-obese Koreans [39]. G82S polymorphism in the RAGE gene is associated with diabetic retinopathy in Chinese population [40], but no positive association between the polymorphisms at 82G/S and the presence and severity of CAD [41]. The association of the G82S polymorphism of RAGE with diabetic retinopathy was confirmed in the population of southern India [42]. However, in the Framingham offspring study, the $82 \mathrm{~S}$ did not demonstrate positive association with the incidence of cardiovascular disease in diabetic or non-diabetic subjects [43]. A meta-analysis revealed no association between the RAGE -429T/C, -374T/A and G82S polymorphisms and coronary heart disease (CHD) risk [44]. A very recent showed that only one polymorphism of RAGE gene at rs1035798 (T>C), rather than the three loci in our study, had a significant association with the stroke subtype, but not with overall IS in Caucasian population. Several reasons may possibly account for the discrepancy between this study and ours: 1 . Ethnic differences: Several studies reported that the genotype distribution of RAGE gene was quite variable among ethnic populations, especially between Caucasian and Chinese [45-48]. 2. Enrollment: We enrolled only patients with first-ever IS, no recurrent IS were included in our study. However, more likely, the association of RAGE gene polymorphism and cardiovascular diseases and vasculopathy is ethnic and disease specific. Thus, multi-center study with larger samples is warranted to better address the role of RAGE polymorphism in vascular disease development.

Recently, inflammation has received increasing attention as a cause of atherosclerosis, coronary artery disease, and stroke. Several inflammatory biomarkers, including CRP, IL-6 and PAI-1 have been identified as predictors of the risk for stroke [49-52]. Blockade of 
inflammatory cytokine, e.g., interleukin-1, or of neutrophil chemotaxis, has reduced infarct volume in models of stroke [53]. Recent studies reported the RAGE G82S polymorphism results in the enhancement of pro-inflammatory mechanisms in immune/ inflammatory diseases and vascular injury. There was a remarkable association of the G82S variant with elevated serum CRP levels, implying that the prevalence of RAGE $82 \mathrm{~S}$ allelic variation may influence susceptibility to vascular disorders by affecting vascular inflammation [41]. Soluble RAGE (sRAGE) is inversely associated with chronic inflammatory state, diabetes, atherosclerosis and metabolic syndrome and may neutralize the AGEs-mediated damage by acting as a decoy [54]. The RAGE $82 \mathrm{~S}$ allele up-regulates the inflammatory response on ligand binding and might enhance pro-inflammatory mechanisms in immune/ inflammatory diseases [37]. A previous study showed the sRAGE concentrations were highest in subjects with the G/G genotype, medium in those with the G/S and lowest in S/S genotype carriers [39]. CRP has evolved as an inflammatory risk marker of cardiovascular disease. Hou et al. reported that hypertensive patients had higher serum hs-CRP levels than controls with normal blood levels [55]. The serum CRP was significantly associated with the G82S variant in the Chinese Han population with CAD [41]. Serum CRP concentration has been reported to be in relation to ischemic stroke subtype. CRP levels were significantly higher for all ischemic stroke subtypes compared with controls [56]. In obese subjects, 82S/S carriers showed significantly higher concentrations of AGEs and hs-CRP than G allele carriers, whereas these phenomenon were not observed in non-obese subjects, suggesting the association between 82G/S genetic variant and CRP may be affected by external conditions [54]. AGEs can induce the expression of IL- 6 through the RAGE activated pathways in human OA chondrocytes [57]. 82S allele of RAGE genetic variants was reported to related to increased IL-6 and tumor necrosis factor-alpha levels in diabetic patients with CAD [58]. PAI-1 is the major physiological inhibitor for fibrinolysis, which is also implicated in inflammation and tissue remodeling. AGE has the ability to cause platelet aggregation and fibrin stabilization, resulting in a predisposition to thrombogenesis [59]. RAGE is one of the key factors implicated in the up-regulation of PAI-1 in vascular endothelial cells under diabetes-associated metabolic stress [60]. In the present study, we found that the 82S/S homozygote carriers had a lower sRAGE level, higher IL-6, hs-CRP and PAI-1 levels, suggesting a higher inflammatory status in $82 \mathrm{~S} / \mathrm{S}$ carriers compared with the G/S and G/G genotype carriers. We postulate that the 82G/S polymorphism of RAGE gene regulate the aforementioned inflammatory cytokine expressions, causing different inflammation levels in respective carriers thus affects the predisposition of ischemic stroke.

Several limitations should be addressed. This is a small-scale case-control study, the conclusion warrants further duplication in larger scale study or, better in different ethnic populations. Secondly, this is a hospital-based study, rather than a population-based study. The enrollment bias may naturally have bias. Finally, we enrolled only Chinese subjects, thus the conclusion may not suit the other ethnic populations.

In conclusion, in the present study, we explored the role of polymorphisms of RAGE gene in determining the susceptibility to ischemic stroke. We found that the presence of 82Ser/ Ser homozygotes had an increased risk for stroke. No significant difference of genotype distributions and alleles frequencies of $-429 \mathrm{~T} / \mathrm{C}$ and $-374 \mathrm{~T} / \mathrm{A}$ between stroke and control subjects. The 82S/S was associated with lower sRAGE level and higher IL-6, hs-CRP and PAI-1 levels compared with the other two genotypes. These findings suggest that the $82 \mathrm{G} / \mathrm{S}$ may be used as a genetic marker for the prediction of stroke occurrence in high risk subjects.

\section{Conflicts of Interest}

The authors confirm that there are no conflicts of interest. 


\section{Cellular Physiology and Biochemistry}

Cui et al.: RAGE Gene Polymorphism and the Susceptibility to IS

\section{References}

1 Ankolekar S, Rewell S, Howells DW, Bath PM: The influence of stroke risk factors and comorbidities on assessment of stroke therapies in humans and animals. Int J Stroke 2012;7:386-397.

2 Rundek T, Sacco RL: Risk factor management to prevent first stroke. Neurol Clin 2008;26:1007-1045, ix.

3 Bevan S, Markus HS: Genetics of common polygenic ischaemic stroke: current understanding and future challenges. Stroke Res Treat 2011;2011:179061.

-4 Huriletemuer H, Zhang C, Niu G, Zhao S, Hurile H: Gene polymorphisms and related risk factors in Mongolian hypertensive stroke patients. Neurosciences (Riyadh) 2010;15:184-189.

-5 Indrajaya T: The Role of ACE Gene Polymorphism on Pathogenesis of Ischemic Stroke. Acta Med Indones 2011;43:152-157.

6 Cheong MY, Bang OS, Cha MH, Park YK, Kim SH, Kim YJ: Association of the adiponectin gene variations with risk of ischemic stroke in a Korean population. Yonsei Med J 2011;52:20-25.

-7 Barr TL, Conley Y, Ding J, Dillman A, Warach S, Singleton A, Matarin M: Genomic biomarkers and cellular pathways of ischemic stroke by RNA gene expression profiling. Neurology 2010;75:1009-1014.

8 Ji R, Jia J, Ma X, Wu J, Zhang Y, Xu L: Genetic variants in the promoter region of the ALOX5AP gene and susceptibility of ischemic stroke. Cerebrovasc Dis 2011;32:261-268.

-9 Ormstad H, Aass HC, Lund-Sorensen N, Amthor KF, Sandvik L: Erratum to: Serum levels of cytokines and C-reactive protein in acute ischemic stroke patients, and their relationship to stroke lateralization, type, and infarct volume. J Neurol 2011;258:677-685.

10 Tuttolomondo A, Di Raimondo D, di Sciacca R, Pinto A, Licata G: Inflammatory cytokines in acute ischemic stroke. Curr Pharm Des 2008;14:3574-3589.

11 Roquer J, Cuadrado-Godia E, Giralt-Steinthauer E, Jimena S, Jimenez-Conde J, Martinez-Rodriguez JE, Ois A, Rodríguez-Campello A: Previous infection and stroke: a prospective study. Cerebrovasc Dis 2012;33:310315.

-12 Worthmann H, Tryc AB, Goldbecker A, Ma YT, Tountopoulou A, Hahn A, Dengler R, Lichtinghagen R, Weissenborn K: The temporal profile of inflammatory markers and mediators in blood after acute ischemic stroke differs depending on stroke outcome. Cerebrovasc Dis 2010;30:85-92.

13 Schmidt AM, Yan SD, Yan SF, Stern DM: The biology of the receptor for advanced glycation end products and its ligands. Biochim Biophys Acta 2000;1498:99-111.

14 Lindsey JB, Cipollone F, Abdullah SM, McGuire DK: Receptor for advanced glycation end-products (RAGE) and soluble RAGE (sRAGE): cardiovascular implications. Diab Vasc Dis Res 2009;6:7-14.

- 15 Lalla E, Lamster IB, Stern DM, Schmidt AM: Receptor for advanced glycation end products, inflammation, and accelerated periodontal disease in diabetes: mechanisms and insights into therapeutic modalities. Ann Periodontol 2001;6:113-118.

16 Park IH, Yeon SI, Youn JH, Choi JE, Sasaki N, Choi IH, Shin JS: Expression of a novel secreted splice variant of the receptor for advanced glycation end products (RAGE) in human brain astrocytes and peripheral blood mononuclear cells. Mol Immunol 2004;40:1203-1211.

17 Wang MY, Ross-Cisneros FN, Aggarwal D, Liang CY, Sadun AA: Receptor for advanced glycation end products is upregulated in optic neuropathy of Alzheimer's disease. Acta Neuropathol 2009;118:381-389. Hassid BG, Nair MN, Ducruet AF, Otten ML, Komotar RJ, Pinsky DJ, Schmidt AM, Yan SF, Connolly ES: Neuronal RAGE expression modulates severity of injury following transient focal cerebral ischemia. J Clin Neurosci 2009;16:302-306.

19 Zhai DX, Kong QF, Xu WS, Bai SS, Peng HS, Zhao K, Li GZ, Wang DD, Sun B, Wang JH, Wang GY, Li HL: RAGE expression is up-regulated in human cerebral ischemia and pMCAO rats. Neurosci Lett 2008;445:117-121.

20 Muhammad S, Barakat W, Stoyanov S, Murikinati S, Yang H, Tracey KJ, Bendszus M, Rossetti G, Nawroth PP, Bierhaus A, Schwaninger M: The HMGB1 receptor RAGE mediates ischemic brain damage. J Neurosci 2008;28:12023-12031.

21 Kamide T, Kitao Y, Takeichi T, Okada A, Mohri H, Schmidt AM, Kawano T, Munesue S, Yamamoto Y, Yamamoto H, Hamada J, Hori O: RAGE mediates vascular injury and inflammation after global cerebral ischemia. Neurochem Int 2012;60:220-228.

22 Park HY, Yun KH, Park DS: Levels of Soluble Receptor for Advanced Glycation End Products in Acute Ischemic Stroke without a Source of Cardioembolism. J Clin Neurol 2009;5:126-132. 
Cui et al.: RAGE Gene Polymorphism and the Susceptibility to IS

23 Yang SJ, Kim S, Hwang SY, Kim TN, Choi HY, Yoo HJ, Seo JA, Kim SG, Kim NH, Baik SH, Choi DS, Choi KM: Association between sRAGE, esRAGE levels and vascular inflammation: Analysis with (18) F-fluorodeoxyglucose positron emission tomography. Atherosclerosis 2012;220:402-406.

24 Gaens KH, Ferreira I, van der Kallen CJ, van Greevenbroek MM, Blaak EE, Feskens EJ, Dekker JM, Nijpels G, Heine RJ, Hart LM, de Groot PG, Stehouwer CD, Schalkwijk CG: Association of polymorphism in the receptor for advanced glycation end products (RAGE) gene with circulating RAGE levels. J Clin Endocrinol Metab 2009;94:5174-5180.

25 Poon PY, Szeto CC, Chow KM, Kwan BC, Li PK. Relation between polymorphisms of receptor for advanced glycation end products (RAGE) and cardiovascular diseases in Chinese patients with diabetic nephropathy. Clin Nephrol 2010;73:44-50.

26 Prevost G, Fajardy I, Besmond C, Balkau B, Tichet J, Fontaine P, Danze PM, Marre M: Polymorphisms of the receptor of advanced glycation endproducts (RAGE) and the development of nephropathy in type 1 diabetic patients. Diabetes Metab 2005;31:35-39.

27 Prasad P, Tiwari AK, Kumar KM, Ammini AC, Gupta A, Gupta R, Thelma BK: Association analysis of ADPRT1, AKR1B1, RAGE, GFPT2 and PAI-1 gene polymorphisms with chronic renal insufficiency among Asian Indians with type-2 diabetes. BMC Med Genet 2010;11:52. doi: 10.1186/1471-2350-11-52.

28 Cohen CR, Diel VB, La Porta VL, Rohde LE, Biolo A, Clausell N, Dos Santos KG: Association study of polymorphisms in the receptor for advanced glycation end-products (RAGE) gene with susceptibility and prognosis of heart failure. Gene 2012;510:7-13.

29 dos Santos KG, Canani LH, Gross JL, Tschiedel B, Pires Souto KE, Roisenberg I: The -374A allele of the receptor for advanced glycation end products gene is associated with a decreased risk of ischemic heart disease in African-Brazilians with type 2 diabetes. Mol Genet Metab 2005;85:149-156.

-30 Adams HP Jr, Bendixen BH, Kappelle LJ, Biller J, Love BB, Gordon DL, Marsh EE $3^{\text {rd }}$ :Classification of subtype of acute ischemic stroke. Definitions for use in a multicenter clinical trial. TOAST. Trial of Org 10172 in Acute Stroke Treatment. Stroke 1993;24:35-41.

- 31 Rouissi K, Bahria IB, Bougatef K, Marrakchi R, Stambouli N, Hamdi K,Cherif M, Ben Slama MR, Sfaxi M, Othman FB, Chebil M, Elgaaied AB, Ouerhani S: The effect of tobacco, XPC, ERCC2 and ERCC5 genetic variants in bladder cancer development. BMC Cancer 2011;11:101.

-32 Hudson BI, Stickland MH, Futers TS, Grant PJ: Study of the -429 T/C and -374 T/A receptor for advanced glycation end products promoter polymorphisms in diabetic and nondiabetic subjects with macrovascular disease. Diabetes Care 2001;24:2004.

-33 Gu H, Yang L, Sun Q Zhou B, Tang N, Cong R, Zeng Y, Wang B: Gly82Ser polymorphism of the receptor for advanced glycation end products is associated with an increased risk of gastric cancer in a Chinese population. Clin Cancer Res 2008;14:3627-3632.

-34 Shi YY, He L: SHEsis, a powerful software platform for analyses of linkage disequilibrium, haplotype construction, and genetic association at polymorphism loci. Cell Res 2005;15:97-98.

-35 Saitoh E, Matsui A, Inao M, Mimura S, Koh H, Ohno A, Nagoshi S, Kayano H, Yoshimoto T, Mochida S, Fujiwara K: Extrahepatic manifestations in transgenic mice of osteopontin in hepatocytes-A clue to advent of pathological state in various organs of chronic hepatitis C patients. Hepatol Res 2005;31:197-202.

-36 Hudson BI, Stickland MH, Grant PJ: Identification of polymorphisms in the receptor for advanced glycation end products (RAGE) gene: prevalence in type 2 diabetes and ethnic groups. Diabetes 1998;47:1155-1157.

37 Hofmann MA, Drury S, Hudson BI, Gleason MR, Qu W, Lu Y, Lalla E, Chitnis S, Monteiro J, Stickland MH, Bucciarelli LG, Moser B, Moxley G, Itescu S, Grant PJ,Gregersen PK, Stern DM, Schmidt AM: RAGE and arthritis: the G82S polymorphism amplifies the inflammatory response. Genes Immun 2002;3:123-135.

-38 Hou XW, Jiang Y, Wang LF, Xu HY, Lin HM, He XY, He JJ, Zhang S: Protective role of granulocyte colonystimulating factor against adriamycin induced cardiac, renal and hepatic toxicities. Toxicol Lett 2009;187:40-44.

-39 Jang Y, Kim JY, Kang SM, Kim JS, Chae JS, Kim OY, Koh SJ, Lee HC, Ahn CW, Song YD, Lee JH: Association of the Gly82Ser polymorphism in the receptor for advanced glycation end products (RAGE) gene with circulating levels of soluble RAGE and inflammatory markers in nondiabetic and nonobese Koreans. Metabolism 2007;56:199-205.

40 Zhang HM, Chen LL, Wang L, Liao YF, Wu ZH, Ye F, Xu S, Yi LL: Association of 1704G/T and G82S polymorphisms in the receptor for advanced glycation end products gene with diabetic retinopathy in Chinese population. J Endocrinol Invest 2009;32:258-262. 
Cui et al.: RAGE Gene Polymorphism and the Susceptibility to IS

41 Gao J, Shao Y, Lai W, Ren H, Xu D: Association of polymorphisms in the RAGE gene with serum CRP levels and coronary artery disease in the Chinese Han population. J Hum Genet 2010;55:668-675.

-42 Balasubbu S, Sundaresan P, Rajendran A, Ramasamy K, Govindarajan G, Perumalsamy N, Hejtmancik JF: Association analysis of nine candidate gene polymorphisms in Indian patients with type 2 diabetic retinopathy. BMC Med Genet 2010;11:158.

-43 Hofmann MA, Yang Q, Harja E, Kedia P, Gregersen PK, Cupples LA, Schmidt AM, Hudson BI: The RAGE Gly82Ser polymorphism is not associated with cardiovascular disease in the Framingham offspring study. Atherosclerosis 2005;182:301-305.

-44 Wang J, Zou L, Song Z, Lang X, Huang S, Lu F, Han L, Xu Z: Meta-analysis of RAGE gene polymorphism and coronary heart disease risk. PLoS One 2012;7:e50790.

45 Holla LI, Kankova K, Fassmann A, Buckova D, Halabala T, Znojil V, Vanek J: Distribution of the receptor for advanced glycation end products gene polymorphisms in patients with chronic periodontitis: a preliminary study. J Periodontol 2001;72:1742-1746.

46 Zhang S, Hou X, Zi S, Wang Y, Chen L, Kong B: Polymorphisms of Receptor for Advanced Glycation end Products and Risk of Epithelial Ovarian Cancer in Chinese Patients. Cell Physiol Biochem 2013;31:525-531.

47 Xu Q, Xue F, Yuan B, Zhang L, Li J, He Z: The interaction between RAGE gene polymorphisms and HPV infection in determining the susceptibility of cervical cancer in a Chinese population. Cancer Biomark 2012;11:147-153.

-48 Daborg J, von Otter M, Sjolander A, Nilsson S, Minthon L, Gustafson DR, Skoog I, Blennow K, Zetterberg H: Association of the RAGE G82S polymorphism with Alzheimer's disease. J Neural Transm 2010;117:861867.

49 Pola R: Inflammatory markers for ischaemic stroke. Thromb Haemost 2009;101:800-801.

-50 Knottnerus IL, Govers-Riemslag JW, Hamulyak K, Rouhl RP, Staals J, Spronk HM, van Oerle R, van Raak EP, Lodder J, ten Cate H, van Oostenbrugge RJ: Endothelial activation in lacunar stroke subtypes. Stroke 2010;41:1617-1622.

-51 Jovanovic ZB, Ilic M, Zidverc-Trajkovic J, Pavlovic AM, Mijajlovic M, Steric N, Stankovic S, BeslacBumbasirevic L, Kostic VS: [Plasminogen activator inhibitor-1 in the evolution of stroke]. Srp Arh Celok Lek 2004;132:143-147.

-52 Rajeshwar K, Kaul S, Al-Hazzani A, Babu MS, Balakrishna N, Sharma V, Jyothy A, Munshi A: C-reactive protein and nitric oxide levels in ischemic stroke and its subtypes: correlation with clinical outcome. Inflammation 2012;35:978-984.

-53 Muir KW, Tyrrell P, Sattar N, Warburton E: Inflammation and ischaemic stroke. Curr Opin Neurol 2007;20:334-342.

54 Kim OY, Jo SH, Jang Y, Chae JS, Kim JY, Hyun YJ, Lee JH: G allele at RAGE SNP82 is associated with proinflammatory markers in obese subjects. Nutr Res 2009;29:106-113.

-55 Hou XW, Wang LF, Wang N, Pang D, Hui B, Zhou YL, He X: The G501C polymorphism of oxidized LDL receptor gene [OLR-1] is associated with susceptibility and serum C-reactive protein concentration in Chinese essential hypertensives. Clin Chim Acta 2008;388:200-203.

-56 Ladenvall C, Jood K, Blomstrand C, Nilsson S, Jern C, Ladenvall P: Serum C-reactive protein concentration and genotype in relation to ischemic stroke subtype. Stroke 2006;37:2018-2023.

-57 Rasheed Z, Akhtar N, Haqqi TM: Advanced glycation end products induce the expression of interleukin-6 and interleukin- 8 by receptor for advanced glycation end product-mediated activation of mitogen-activated protein kinases and nuclear factor-kappaB in human osteoarthritis chondrocytes. Rheumatology (Oxford) 2011;50:838-851.

-58 Peng WH, Lu L, Wang LJ, Yan XX, Chen QJ, Zhang Q, Zhang RY, Shen WF: RAGE gene polymorphisms are associated with circulating levels of endogenous secretory RAGE but not with coronary artery disease in Chinese patients with type 2 diabetes mellitus. Arch Med Res 2009;40:393-398.

-59 Yamagishi S, Fujimori H, Yonekura H, Yamamoto Y, Yamamoto H: Advanced glycation endproducts inhibit prostacyclin production and induce plasminogen activator inhibitor-1 in human microvascular endothelial cells. Diabetologia 1998;41:1435-1441.

60 Sangle GV, Zhao R, Mizuno TM, Shen GX: Involvement of RAGE, NADPH oxidase, and Ras/Raf-1 pathway in glycated LDL-induced expression of heat shock factor-1 and plasminogen activator inhibitor-1 in vascular endothelial cells. Endocrinology 2010;151:4455-66. 